\title{
Dynamic of a two-strain COVID-19 model with vaccination
}

\author{
Stéphane Tchoumi $^{1}$, Herieth rwezaula ${ }^{2}$, and Jean M. Tchuenche ${ }^{3}$ \\ ${ }^{1}$ University of Ngaoundere \\ ${ }^{2}$ University of Dar es Salaam \\ ${ }^{3}$ University of the Witwatersrand
}

October 23, 2021

\begin{abstract}
COVID-19 is a respiratory illness caused by an RNA virus prone to mutations. In December 2020, variants with different characteristics that could affect transmissibility emerged around the world. To address this new dynamic of the disease, we formulate and analyze a mathematical model of a two-strain COVID- 19 transmission dynamics with strain 1 vaccination. The model is theoretically analyzed and sufficient conditions for the stability of its equilibria are derived. In addition to the disease-free and endemic equilibria, the model also has single-strain 1 and strain 2 endemic equilibria. Using the center manifold theory, it is shown that the model does not exhibit the phenomenon of backward bifurcation, and global stability of the model equilibria when the basic reproduction number $\mathrm{R} 0$ is either less or greater than unity as the case maybe are proved using various approaches. Simulations to support the model theoretical results are provided. We calculate the basic reproductive number for both strains R 1 and R 2 independently. Results indicate that - both strains will persist when R $1>1$ and R $2>$ 1 - Stain 2 could establish itself as the dominant strain if $\mathrm{R} 1<1$ and $\mathrm{R} 2>1$, or when $\mathrm{R} 2$ is at least two times greater than $\mathrm{R} 1$. However, with the current knowledge of the epidemiology of the COVID-19 pandemic and the availability of treatment and an effective vaccine against strain 1, it is expected that eventually, strain 2 will likely be eradicated in the population due to de novo herd immunity provided the threshold parameter R 2 is controlled to remain below unity.
\end{abstract}

\section{Hosted file}

Project_1 Oct 2021.pdf available at https://authorea.com/users/442561/articles/542798dynamic-of-a-two-strain-covid-19-model-with-vaccination

\section{Hosted file}

Project_1 Oct 2021.tex available at https://authorea.com/users/442561/articles/542798dynamic-of-a-two-strain-covid-19-model-with-vaccination 

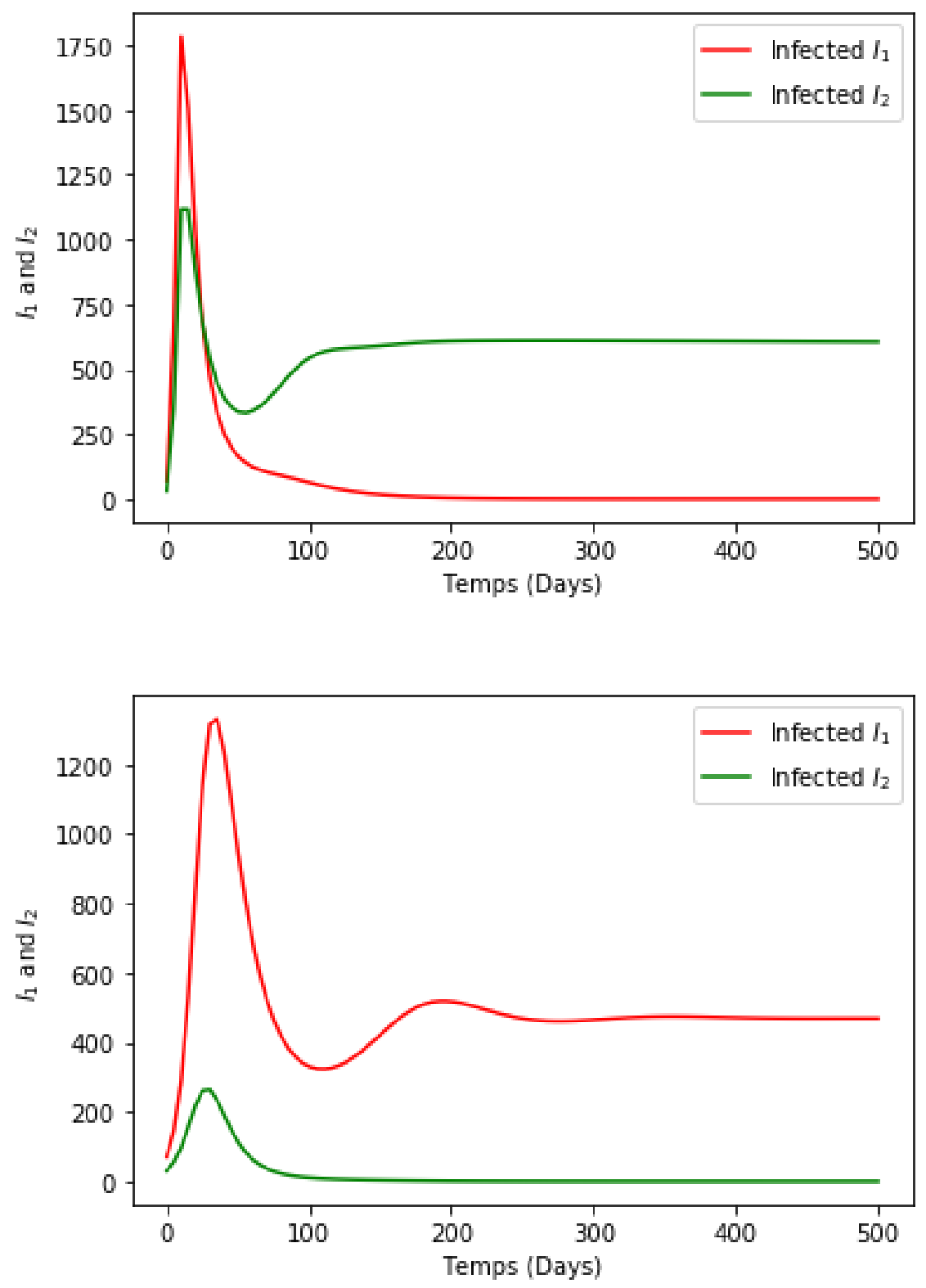

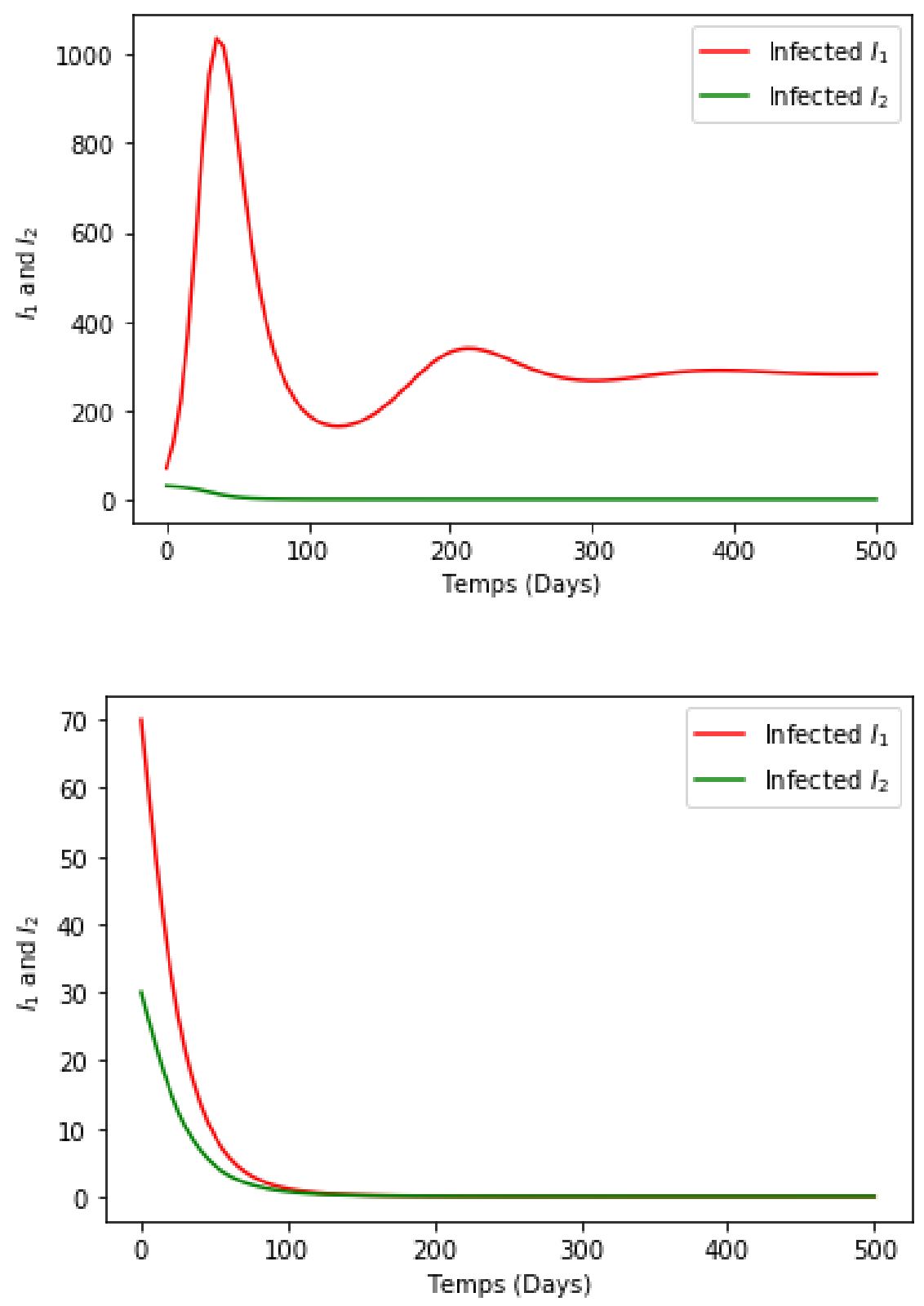

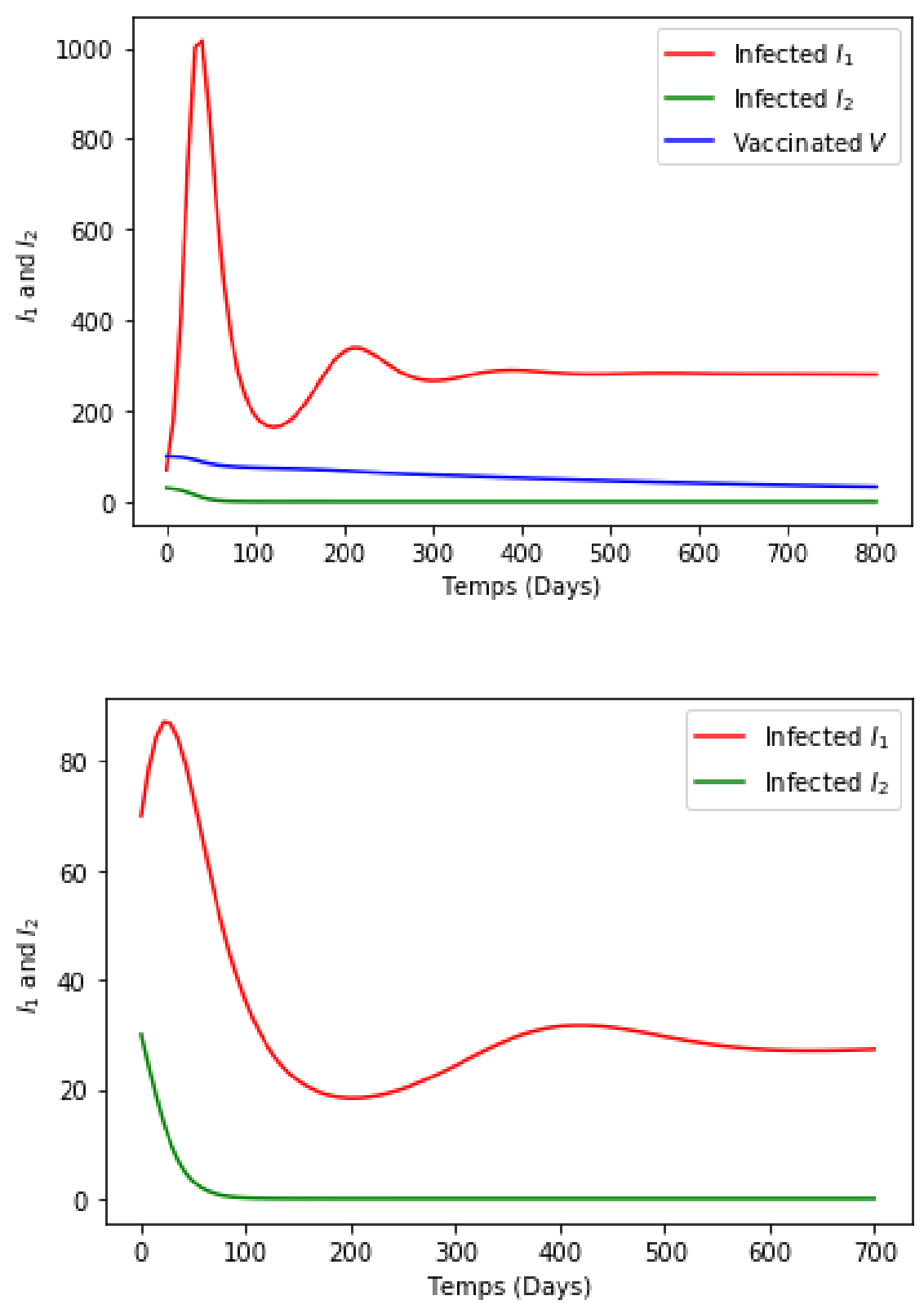

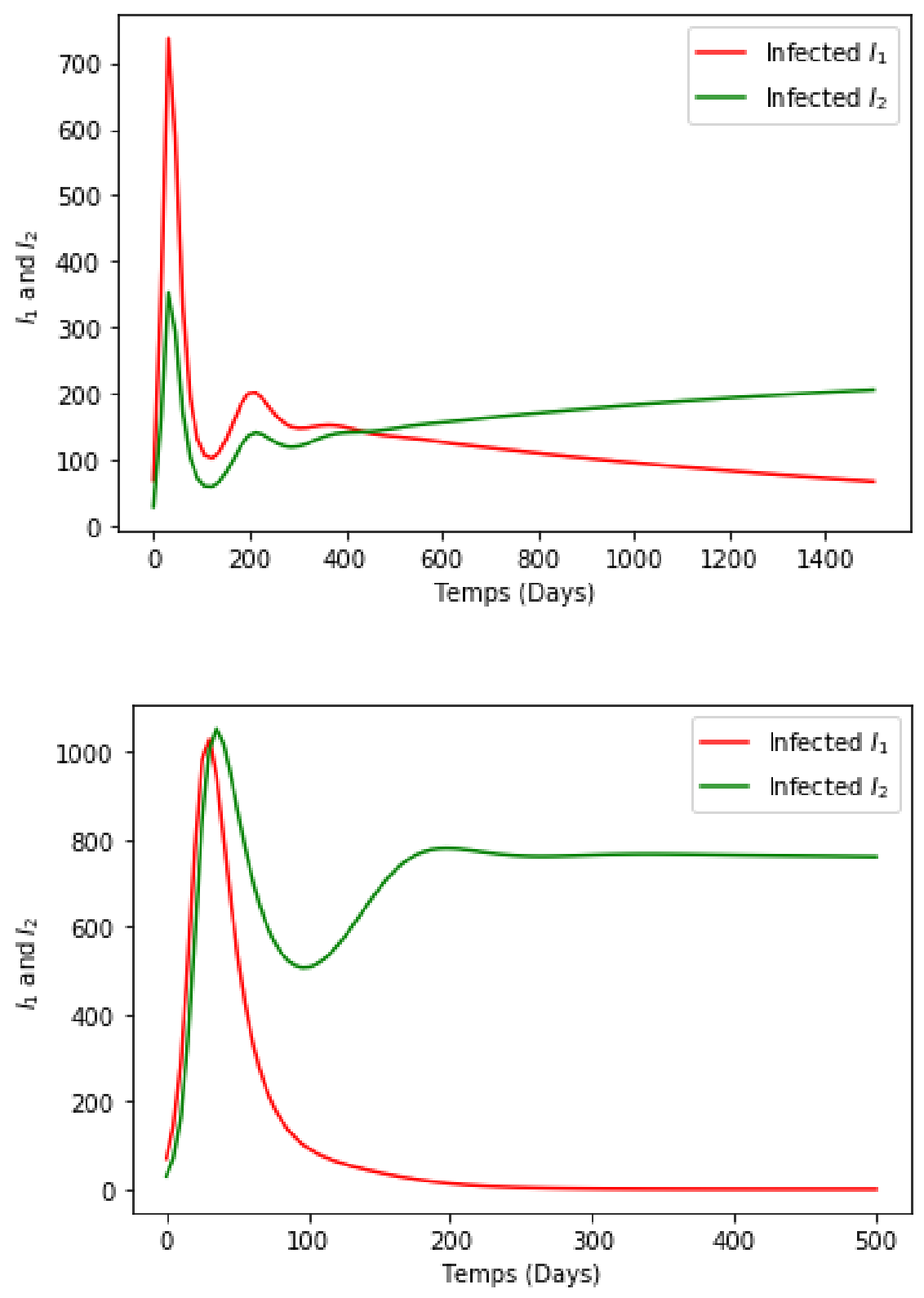

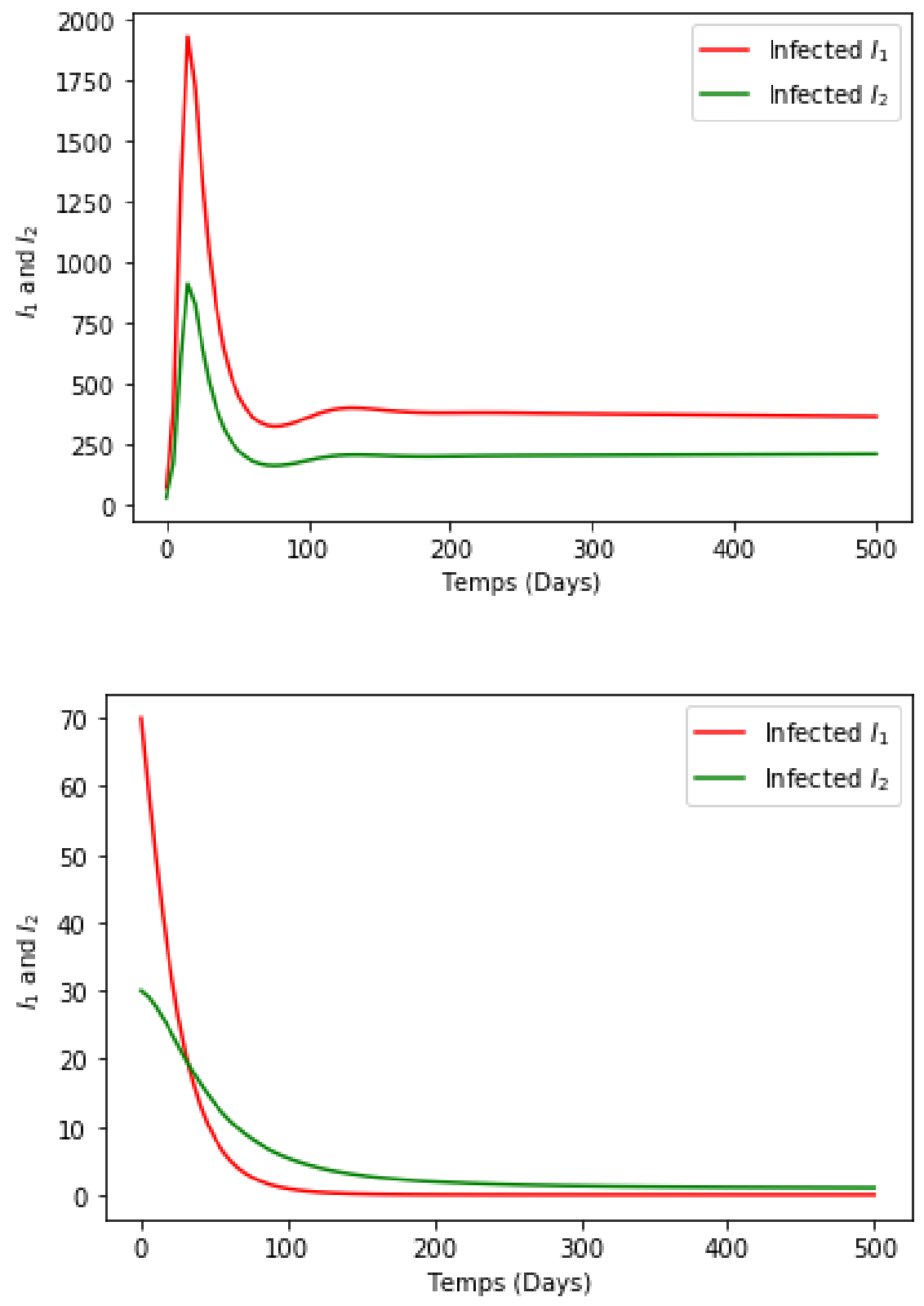

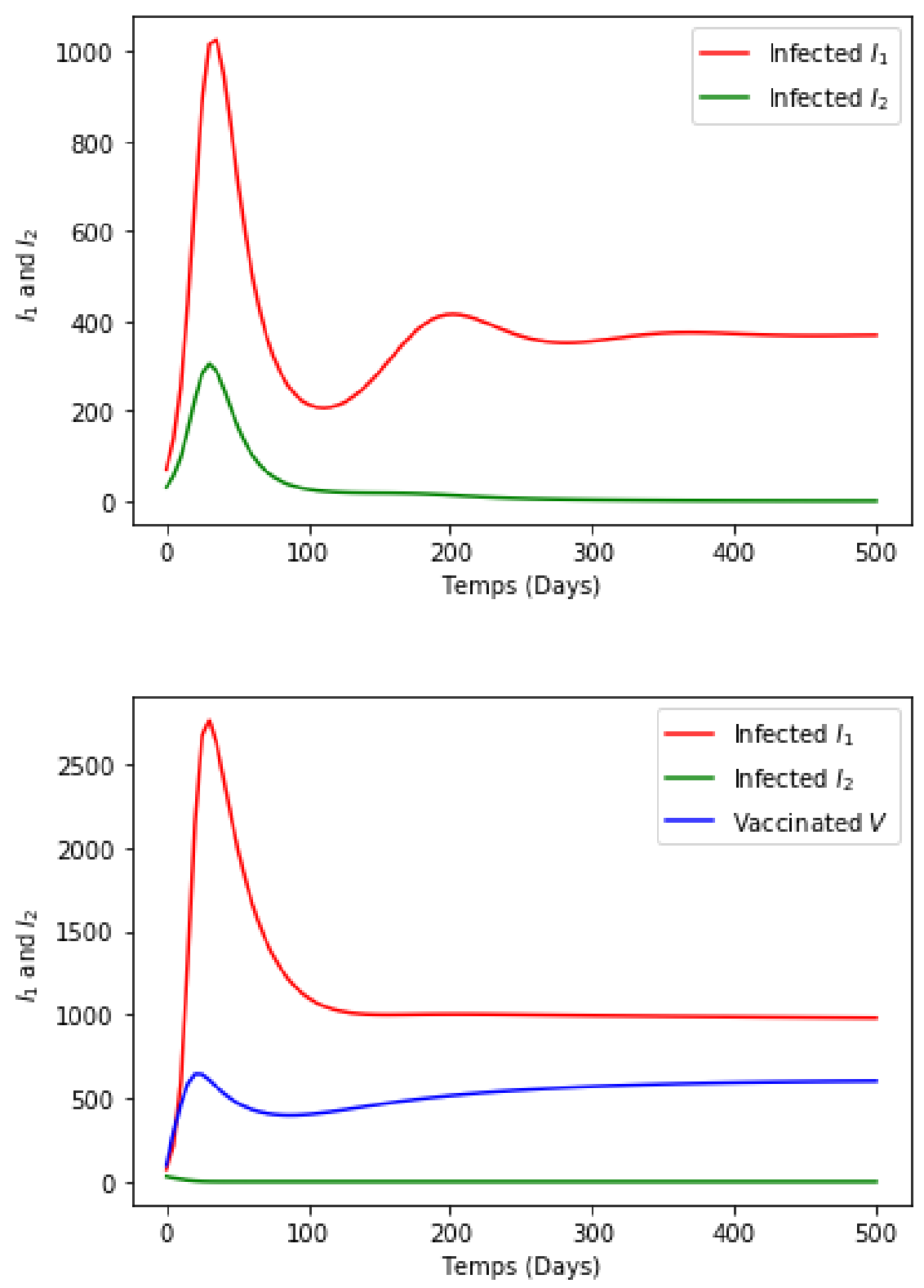


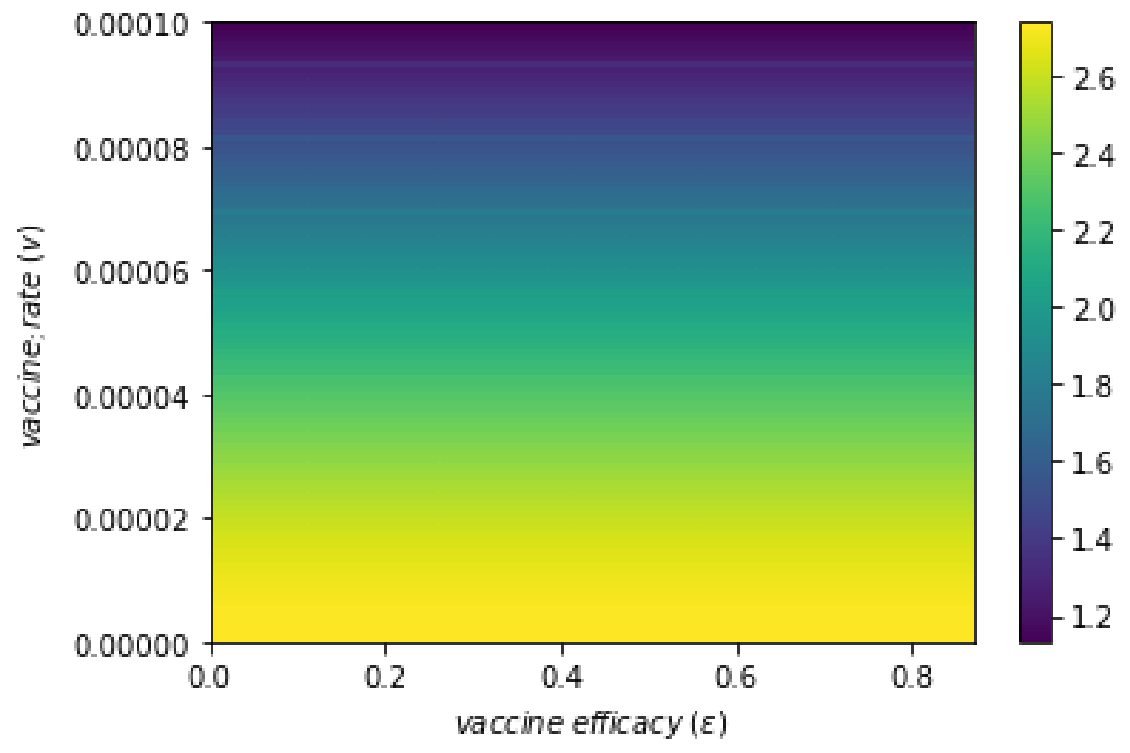

